\title{
IL-17A regulates Eimeria tenella schizont maturation and migration in avian coccidiosis
}

\author{
Emilio del Cacho ${ }^{1 *}$, Margarita Gallego ${ }^{1}$, Hyun Soon Lillehoj ${ }^{2}$, Joaquín Quílez ${ }^{1}$, Erik P Lillehoj ${ }^{3}$, Ana Ramo \\ and Caridad Sánchez-Acedo ${ }^{1}$
}

\begin{abstract}
Although IL17A is associated with the immunological control of various infectious diseases, its role in host response to Eimeria infections is not well understood. In an effort to better dissect the role of IL 17A in host-pathogen interactions in avian coccidiosis, a neutralizing antibody (Ab) to chicken IL17A was used to counteract IL17A bioactivity in vivo. Chickens infected with Eimeria tenella and treated intravenously with IL17A Ab, exhibited reduced intracellular schizont and merozoite development, diminished lesion score, compared with untreated controls. Immunohistological evaluation of cecal lesions in the parasitized tissues indicated reduced migration and maturation of second-generation schizonts and reduced lesions in lamina propria and submucosa. In contrast, untreated and infected chickens had epithelial cells harboring second-generation schizonts, which extend into the submucosa through muscularis mucosa disruptions, maturing into second generation merozoites. Furthermore, IL17A Ab treatment was associated with increased parameters of Th1 immunity (IL2- and IFNY- producing cells), reduced levels of reactive oxygen species (ROS), and diminished levels of serum matrix metalloproteinase-9 (MMP-9). Finally, schizonts from untreated and infected chickens expressed S100, Wiskott-Aldrich syndrome protein family member 3 (WASF3), and heat shock protein-70 (HSP70) proteins as merozoites matured, whereas the expression of these proteins was absent in IL17A Ab-treated chickens. These results provide the first evidence that the administration of an IL17A neutralizing Ab to E. tenella-infected chickens inhibits the migration of parasitized epithelial cells, markedly reduces the production of ROS and MMP-9, and decreases cecal lesions, suggesting that IL17A might be a potential therapeutic target for coccidiosis control.
\end{abstract}

\section{Introduction}

The coccidial parasite, Eimeria tenella, is a significant cause of intestinal disease in chickens and hens worldwide. Eimeria tenella is an intracellular obligate protozoan parasite having a complex life cycle of seven days, during which it undergoes intracellular development and proliferates through characteristic intracellular stages confined to the cecal epithelium. Eimeria tenella initially invades the epithelial cells lining in the lumen of the crypts of Lieberkhün. The ensuing life cycle of the parasite involves detachment of the parasitized cells from the epithelial layer and their migration to the underlying connective tissue of the lamina propria (LP), where maturation to schizonts occurs [1]. Early development of schizonts is accompanied by considerable hypertrophy and the modification of the host cell, which survives in

\footnotetext{
* Correspondence: edelcach@unizar.es

${ }^{1}$ Department of Animal Pathology, Faculty of Veterinary Sciences, University

of Zaragoza, Zaragoza, Spain

Full list of author information is available at the end of the article
}

the LP as long as the schizont matures [1]. Schizont maturation takes place as the host cells harboring the parasite migrates through the LP deep into the muscularis mucosa (MM), the boundary between the LP and the submucosa.

The ability of parasitized epithelial cells to detach from the epithelium lining of the crypts, migrate through the basal membrane underneath the epithelium, and invade the LP relies on a complex cascade of molecular events involving a finely tuned interplay between parasite and host cells. Among the factors playing a role in this response, interleukin-17A (IL17A), a proinflammatory cytokine secreted by activated $\mathrm{T}$ helper cells (Th17 type), plays a critical role in host defense against pathogens [2-4]. IL17A transcripts were shown to be highly up-regulated during avian coccidiosis [5,6], and IL17A protein plays a proinflammatory role during noncoccidial protozoan infections [7-9]. Moreover, IL17A induces the production of reactive oxygen species (ROS) [10], and activates the epithelial cell contractile machinery through cytoskeleton rearrangements 
[11] and disruption of intercellular tight junctions [12,13]. It is precisely these properties of IL17A that led us to study its role on E. tenella schizonts maturation and intracellular stage progression in cecal coccidiosis. To evaluate the effects of IL17A on facilitating the detachment of the parasitized cells from the epithelial layer and promoting their subsequent migration through the LP, a IL17A neutralizing $\mathrm{Ab}$ [14] was administered to chickens infected with E. tenella. To further confirm the influence of IL17A on intracellular parasite development and the subsequent parasite-specific immune response, we also evaluated Th1- and Th2-cytokine responses. In addition, the effect of neutralizing local IL17A production on ROS generation in cecal cells was measured to evaluate the role of parasite-induced oxidative stress. Finally, we studied the expression of proteins having a role in cell motility and cytoskeleton rearrangement. These motility-associated proteins included Wiskott-Aldrich syndrome protein family member 3 (WASF3), which is implicated in actin polymerization and cell movement $[15,16]$, heat shock protein-70 (HSP70), a chaperone involved in the folding of newly synthesized proteins and which directly influences WASF3 stability [15], and S100, which belongs to the super-family of acid $\mathrm{Ca}^{2+}$-binding proteins of the EF-hand type which regulates microtubule assembly/disassembly [17]. Moreover, serum MMP-9 levels were measured to evaluate the effect of the IL17A Ab on cell migration through the extracellular matrix. In this report, we provide first evidence that treatment of E. tenella-infected chickens with IL17A neutralizing Ab reduced the motility of schizont-harboring epithelial cells and decreased their migration to deep areas in the LP. These results demonstrate a role for IL17A in the life cycle of $E$. tenella, specifically on schizont maturation and migration.

\section{Materials and methods \\ Animals}

White Leghorn chickens were hatched and reared under Eimeria-free conditions with access to feed and water provided ad libitum. All experiments were performed in accordance with the guidelines approved by the University of Zaragoza Institutional Animal Care and Use Committee.

\section{Parasite}

A strain of E. tenella originally obtained from Merck, Sharp and Dome (Madrid, Spain) was used. Oocysts were propagated, isolated, and sporulated using standard procedures [18]. Chickens were infected with sporulated oocysts that had been stored for less than 4 weeks by oral inoculation into the crop [19].

\section{Experimental design}

One-day old chickens $(n=24)$ were randomly divided into three groups of eight chickens each with equal mean body weights. At 15 days of age, chickens in groups I and II were infected orally into the crop with $1.0 \times 10^{4}$ E. tenella sporulated oocysts per bird. At 3, 4, and 5 days postinfection (dpi), chickens in group I were intravenously injected into the radial vein with $3 \mu \mathrm{g}$ per bird of IL17A $\mathrm{Ab}$ [14] and chickens in group II were intravenously injected with sterile PBS. Chickens in group III served as uninfected noninjected controls and chickens in group II served as noninjected infected controls. At day 5 postinfection (pi), three animals from each group were euthanatized and ceca samples were removed to visualize schizont lesions by both the light and electron microscopy, and blood was collected to quantify IL17A levels in serum. At day 6 pi, five animals from each group were euthanatized and ceca, cecal tonsil (CT), spleen, and Peyer's patch (PP) samples were removed to visualize histopathological ceca lesions, quantify antigen-specific cytokine-secreting cells (IL2, IL4, IL10, and interferon (IFNY), and measure ROS. In addition, at this time point, blood was collected for quantification of IL17A and MMPs. Ceca lesion scores were determined on a graded scale from 0 (none) to 4 (high) in a blinded fashion by two independent observers as described [20]. The complete experimental procedure was repeated three times.

\section{Quantification of IL17A in serum}

Sera for IL17A measurement were collected at days 5 and 6 pi from chickens given a single oral dose of $1.0 \times 10^{4}$ sporulated oocysts of $E$. tenella. Ninety-six-well flatbottom microtiter plates were coated with $100 \mu \mathrm{L}$ of $20 \mu \mathrm{g} / \mathrm{mL}$ of chicken IL17A Ab [14] in $0.1 \mathrm{M}$ carbonate buffer, pH 9.6 for $18 \mathrm{~h}$ at $48{ }^{\circ} \mathrm{C}$, and washed three times with phosphate buffered saline containing $0.05 \%$ Tween20, pH 7.2 (PBS-T). Each well was blocked with $200 \mu \mathrm{L}$ of PBS containing $2 \%(\mathrm{w} / \mathrm{v})$ bovine serum albumin (BSA) for $1 \mathrm{~h}$ at room temperature, and washed three times with PBS-T. Sera $(100 \mu \mathrm{L})$ were added, the plates incubated for $2 \mathrm{~h}$ at room temperature, washed three times, $100 \mu \mathrm{L}$ of horseradish peroxidase (HRP)-conjugated goat anti-mouse IgG ( $\mathrm{H}+\mathrm{L}$; Sigma, St. Louis, MO, USA) in PBS-0.1\% BSA added, and incubated for $1 \mathrm{~h}$ at room temperature. The plates were washed three times, $100 \mu \mathrm{L}$ of $0.01 \%(\mathrm{w} / \mathrm{v})$ 3,3',5,5' -tetramethylbenzidine dihydrochloride (TMB; Sigma) in $0.05 \mathrm{M}$ phosphate-citrate buffer, $\mathrm{pH}$ 5.0, added for $15 \mathrm{~min}$, the reaction stopped with $50 \mu \mathrm{L}$ of $2 \mathrm{M} \mathrm{H}_{2} \mathrm{SO}_{4}$, and the absorbency at $450 \mathrm{~nm}$ read by an automated microtiter plate reader (Bio-Rad, Richmond, CA, USA).

\section{Immunohistochemistry}

\section{Double staining immunohistochemistry}

Ceca samples were frozen in liquid nitrogen. Cryostat sections were made and blocked with normal horse serum for $10 \mathrm{~min}$, rinsed in $\mathrm{PBS}, \mathrm{pH} \mathrm{7.2,} \mathrm{and} \mathrm{endogenous}$ peroxidase was inactivated with $1.7 \% \mathrm{H}_{2} \mathrm{O}_{2}$ in ethanol for 
$30 \mathrm{~min}$. Sections were incubated with fibronectin rabbit Ab (Sigma) (1:100 dilution) at room temperature for 90 min. After washing with PBS, pH7.2, the slides were incubated with biotinylated goat anti-rabbit IgG Ab (Vector, Burlingame, CA, USA) for $30 \mathrm{~min}$. The avidin-biotin peroxidase complex (ABC) (Vector) was applied for $45 \mathrm{~min}$ and the peroxidase reaction was developed with $0.05 \%$ of 3-amino-9-ethylcarbazole substrate in $0.05 \mathrm{M}$ Tris- $\mathrm{HCl}$, $\mathrm{pH}$ 7.6, containing $0.01 \% \mathrm{H}_{2} \mathrm{O}_{2}$ for $10 \mathrm{~min}$. Sections were rinsed in $\mathrm{PBS}, \mathrm{pH}$ 7.2, and incubated with mouse caveolin-1 monoclonal Ab (Santa Cruz Biotechnology, CA, USA) (1:100 dilution) at room temperature for $90 \mathrm{~min}$. After washing with PBS, the slides were incubated with biotinylated goat anti-mouse IgG Ab (Vector) for $30 \mathrm{~min}$. The $\mathrm{ABC}$ (Vector) was applied for $45 \mathrm{~min}$, and the binding sites of the primary $\mathrm{Ab}$ were visualized with $0.2 \mathrm{mg} / \mathrm{mL}$ of $3,3^{\prime}$-diaminobenzidine (DAB) in $0.05 \mathrm{M}$ Tris- $\mathrm{HCl}, \mathrm{pH} 7.6$, containing $0.005 \% \mathrm{H}_{2} \mathrm{O}_{2}$ for five min. As negative controls, sections of all samples were incubated with normal serum instead of the primary Ab, with the remaining procedure being the same. These negative control sections were devoid of positive-staining cells.

\section{Single staining immunohistochemistry}

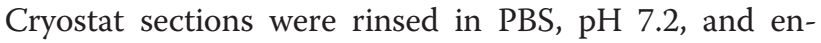
dogenous peroxidase was inactivated with $1.7 \% \mathrm{H}_{2} \mathrm{O}_{2}$ in ethanol for $30 \mathrm{~min}$. The slides were blocked with undiluted normal pig serum at room temperature for 30 min and incubated with primary Ab (1:10 dilution) at $4{ }^{\circ} \mathrm{C}$ for $18 \mathrm{~h}$. As primary antibodies we used S100 mouse monoclonal Ab (Sigma), HSP70 mouse monoclonal Ab (Sigma) or WASF3 rabbit polyclonal Ab (Antibodies-Online, Atlanta, GA). After washing with PBS, $\mathrm{pH7.2}$, the slides were incubated with biotinylated goat anti-mouse or goat anti-rabbit IgG Abs (Vector) for 30 min. The $A B C$ was applied for 45 min and the peroxidase reaction was developed with $\mathrm{DAB}$ as above.

\section{ROS measurement}

Measurement of hydroxyl, peroxyl and other ROS activities was performed using $2^{\prime}, 7^{\prime}$-dichlorofluorescein diacetate (DCFDA) with the ROS assay kit (Abcam, Cambridge, MA, USA). Cecal samples were harvested at day 6 post-immunization, pressed through $250 \mu \mathrm{m}$ mesh screens, and resuspended and washed in GKN buffer $(2.0 \mathrm{mg} / \mathrm{mL}$ glucose, $0.40 \mathrm{mg} / \mathrm{mL} \mathrm{KCl}, 8.0 \mathrm{mg} / \mathrm{mL} \mathrm{NaCl}$, $3.56 \mathrm{mg} / \mathrm{mL} \mathrm{Na}_{2} \mathrm{HPO}_{4}, 0.78 \mathrm{mg} / \mathrm{mL} \mathrm{NaH} \mathrm{PO}_{4}, \mathrm{pH} 7.4$ ) containing 5.0 mM EDTA. Single-cell suspensions were obtained by filtration through a $70 \mu \mathrm{m}$ pore size cell strainer (BD Falcon, Franklin Lakes, NJ, USA) and were purified from dead cells, erythrocytes, and epithelial cells by Percoll density gradient centrifugation [21]. Approximately $2.5 \times 10^{4}$ cells were incubated in $20 \mu \mathrm{M}$ DCFDA for $45 \mathrm{~min}$ at $37{ }^{\circ} \mathrm{C}$ according to the manufacturer's instructions. Incubated cells were then washed with PBS, transferred to microplates, and read on a microplate fluorometer $\left(\lambda_{\mathrm{ex}}=485 \mathrm{~nm}, \lambda_{\mathrm{em}}=535 \mathrm{~nm}\right)$.

\section{Electron microscopy}

Cecal samples were fixed in glutaraldehyde for $90 \mathrm{~min}$, washed in Millonig buffer, and fixed for $30 \mathrm{~min}$ in $1 \%$ osmium tetroxide [22]. After a final washing in buffer and dehydration in ethanol, the fixed tissue was cleared in propylene oxide and embedded in Epon-Araldite (1:1) (Sigma). Semi-thin $(1 \mu \mathrm{m})$ and ultrathin $(40-60 \mathrm{~nm}) \mathrm{sec}-$ tions were made and stained with toluidine blue, uranyl acetate and lead citrate.

\section{Quantification of MMP-9}

Sera for MMP-9 measurement were collected at day 6 pi from uninfected and infected chickens given a single oral dose of $1.0 \times 10^{4}$ sporulated oocysts of E. tenella. Ninety-six well flat-bottom microtiter plates were coated with $100 \mu \mathrm{L}$ of $20 \mu \mathrm{g} / \mathrm{mL}$ of MMP-9 polyclonal $\mathrm{Ab}$ (MyBioSource, San Diego, CA, USA) in $0.1 \mathrm{M}$ carbonate buffer, pH 9.6 for $18 \mathrm{~h}$ at $48{ }^{\circ} \mathrm{C}$, and washed three times with PBS-T. Each well was blocked with $200 \mu \mathrm{L}$ of PBS$\mathrm{BSA}$ ) for $1 \mathrm{~h}$ at room temperature, and washed three times with PBS-T. Sera $(100 \mu \mathrm{L})$ were added, the plates incubated for $2 \mathrm{~h}$ at room temperature, washed three times, $100 \mu \mathrm{L}$ of HRP-conjugated goat anti-rabbit IgG $\mathrm{Ab}(\mathrm{H}+\mathrm{L}$; Sigma $)$ in PBS-0.1\% BSA added, and incubated for $1 \mathrm{~h}$ at room temperature. The plates were washed three times and developed with TMB as above.

\section{Quantification of E. tenella antigen-specific cytokine-secreting cells}

CT, spleen, and PP samples were separately harvested at day 6 post-immunization, pressed through $250 \mu \mathrm{m}$ mesh screens, resuspended and washed in GKN buffer containing 5.0 mM EDTA, and single cell suspensions were purified by Percoll gradient centrifugation as above. For quantification of cytokine-producing cells, $1.0 \times 10^{5}$ cells were cultured for three days in the presence or absence of E. tenella antigens $(100 \mu \mathrm{g} / \mathrm{mL})$ [22] in $0.2 \mathrm{~mL}$ of RPMI 1640 medium. The cells were washed and added to microplates that had previously been coated overnight at $4{ }^{\circ} \mathrm{C}$ with chicken IL2, IL4, IL10, or IFN $\gamma$ Abs, blocked at room temperature for $2 \mathrm{~h}$ with PBS containing $10 \mu \mathrm{g} / \mathrm{mL}$ of BSA and $0.05 \%$ Tween 20 (PBS/BSA $/ \mathrm{T}$ ), and washed three times with PBS. Cytokine enzymelinked immunosorbent spot (ELISPOT) assays were performed as described [22].

\section{Statistical analysis}

Statistical analysis was performed using SAS System for Windows V.9.2. All data were expressed as mean \pm standard deviation (SD) values. Duncan's multiple-range 
test was used to evaluate the differences between treatment groups. Differences between mean values were considered statistically significant at $P<0.05$.

\section{Results}

IL17A neutralizing Ab reduces $E$. tenella-induced serum IL17A

Serum IL17A levels in E. tenella-infected chickens at days 5 and 6 pi were increased compared with uninfected controls (Figure 1). However, IL17A levels were significantly decreased in infected chickens that were given $3 \mu \mathrm{g}$ per bird of IL17A neutralizing $\mathrm{Ab}$ at 3, 4, and 5 dpi, compared with infected nontreated controls.

\section{Effect of IL17A Ab on schizont migration through the cecal wall}

At day 5 pi, when large numbers of schizonts are present in the cecal mucosa, fibronectin-expressing schizonts were identified as they migrated from the epithelial lining of the crypts of Lieberkühn through the cecal wall (Figures 2A and 2B). In infected chickens that were not given the IL17A $\mathrm{Ab}$, schizonts were seen to reach the intestinal MM, the deepest portion of the mucosa (Figures 2A and 2C). In places, the MM was disrupted (Figures $2 \mathrm{~A}$ and $2 \mathrm{C}$ ) and the schizonts extended into the submucosa (SM) (Figures 2A and 2D). Schizonts were clearly observed on both sides of the MM, the mucosa, and SM. These migrating schizonts were mainly immature (Figure 2D). Notably, the LP and SM contained numerous round cells of the immune system, which were observed as prominent dense infiltrates (Figures 2A and 2C). However, in infected chickens treated with IL17A

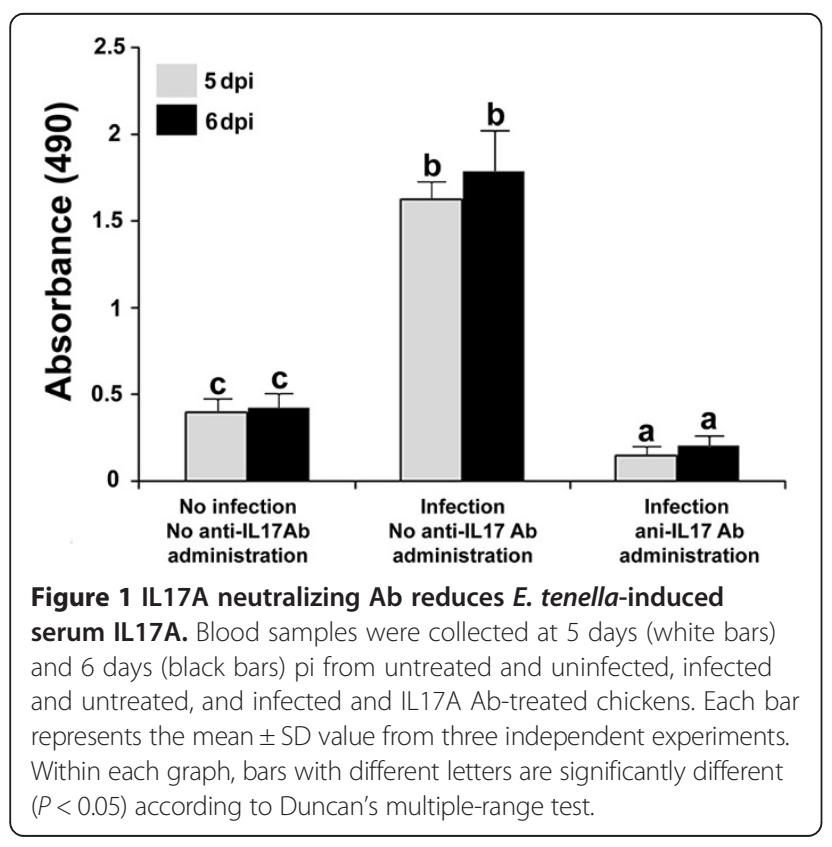

$\mathrm{Ab}$, the LP between the crypts and within the core of each villi contained less cell infiltration (Figures $2 \mathrm{~B}$ and $2 \mathrm{E})$. In addition, epithelial cells harboring schizonts and migrating through the LP did not extend to the SM in IL17A Ab treated chickens. The MM was observed as a continuous line separating the mucosa from the submucosa (Figures $2 \mathrm{~B}$ and 2E). Thus, in infected chickens given IL17A Ab, schizonts were confined within the LP near the epithelium lining the cecal lumen (Figures 2B, $2 \mathrm{E}$, and $2 \mathrm{~F}$ ). These schizonts were both immature and mature, the later being recognized by their development into merozoites (Figure 2F).

At day $6 \mathrm{pi}$, when merozoites were formed and schizont numbers dramatically decreased, the cecal wall was devoid of immunoreactivity for fibronectin (Figures $2 \mathrm{G}$ and $2 \mathrm{H}$ ). In untreated infected chickens (Figure 2G), large numbers of inflammatory cells were observed in both the LP and SM, and the cecal wall was thickened. In addition, frequent disruptions in the MM were observed (Figure 2G). However, in infected chickens that were given IL17A $\mathrm{Ab}$, the round cell infiltrates were fairly inconspicuous within both the LP and SM, and the MM was seen as a continuous line devoid of disruptions (Figure 2H).

\section{Effect of IL17A Ab on expression of proteins involved in cell motility}

In the cecal wall of untreated infected chickens, both mature and immature schizonts, which were observed migrating through the LP, expressed S100, HSP70 and WASF3, proteins involved in cell motility (Figure 3A-C). However, no detectable immunostaining was observed in the tissue samples of IL17A Ab treated birds incubated with anti-WASF3, -HSP70 or -S-100 (Figure 3D).

\section{Effect of IL17A Ab on morphological quantification of schizonts}

Schizonts observed in the cecal wall from untreated infected chickens were $32 \pm 3.7 \mu \mathrm{m}$ in diameter and contained $103 \pm 9.1$ merozoites per schizont (Figure 4A). However, schizonts seen in the cecal wall from infected chickens that were given the IL17A Ab had diameters of $7.5 \pm 1.8 \mu \mathrm{m}$ and contained $9.4 \pm 2.8$ merozoites per schizont (Figure 4B).

\section{Effect of IL17A Ab on ROS production by cecal cells} Increased ROS production was seen at day 6 pi in cecaderived cells of untreated chickens, compared with untreated and uninfected chickens (Figure 5). Significant decreased ROS production was observed in ceca-derived cells from infected chickens that were given IL17A Ab, compared with infected birds that were not given $\mathrm{Ab}$. 

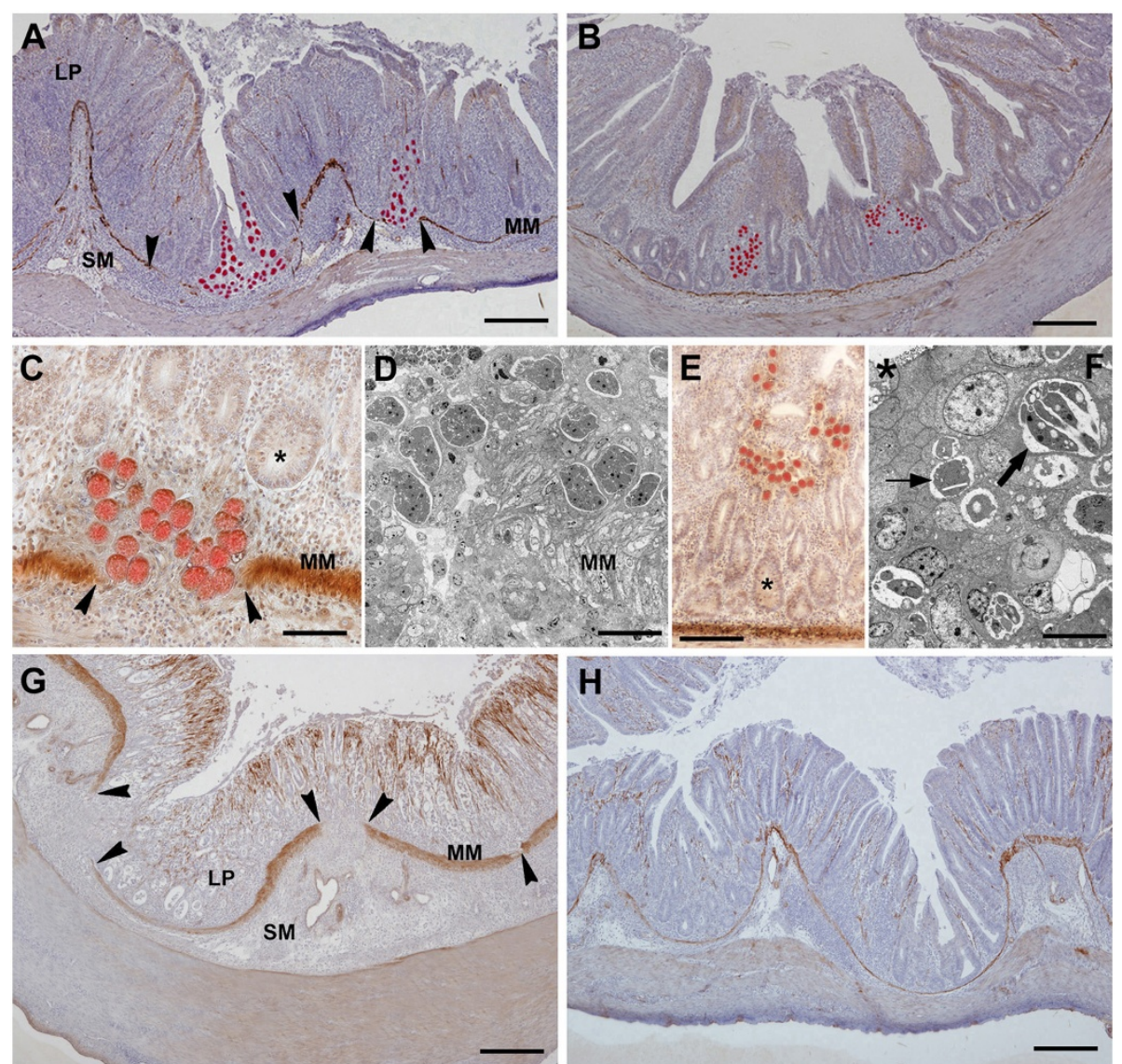

Figure 2 Effect of IL17A Ab on E. tenella schizont migration. Cecal tissue sections from infected chickens were taken at 5 days (A-F) and 6 days $\mathbf{( G , H )}$ pi. Schizonts are observed as round and red structures expressing fibronectin in chickens untreated $(\mathbf{A}, \mathbf{C}, \mathbf{D}, \mathbf{G})$ or IL $17 \mathrm{~A}$ Ab-treated $(\mathbf{B}, \mathbf{E}, \mathbf{F}, \mathbf{H})$. The muscularis mucosa $(\mathrm{MM})$ is visualized as a thin and brown caveolin positive line beneath the base of the crypts. $\mathbf{A}$. Migration of schizonts from the crypt epithelium to the submucosa (SM) through MM disruptions (arrowheads). Note the lamina propria (LP) diffusely infiltrated by numerous immune system cells which extend into the SM. B. Schizont groups which do not reach the SM. Note the cell infiltrates confined to the LP and the continuity of the MM. C. Schizonts, which locate deep in the LP, extend beyond the MM. Lumen of crypt fundi (*). D. Electron micrograph showing the lower portion of the LP where immature schizonts are recognizable. E. Schizonts observed in the upper portion of the LP. Lumen of crypt fundi $(*)$. F. Electron micrograph showing schizonts recognizable as mature (thick arrow) and immature stages (thin arrow). Lumen of a crypt (*) G. Prominent cell infiltrates in the LP and SM. Arrowheads: MM disruptions. H. Light cell infiltrates located in the LP surrounding the crypts. Note inconspicuous infiltrates in the SM and the continuous MM. Bars indicate: $300 \mu \mathrm{m}$ in $\mathbf{A}$ and $\mathbf{B} ; 130 \mu \mathrm{m}$ in $\mathbf{C} ; 50 \mu \mathrm{m}$ in $\mathbf{D} ; 90 \mu \mathrm{m}$ in $\mathbf{E} ; 10 \mu \mathrm{m}$ in $\mathbf{F}$; $230 \mu \mathrm{m}$ in $\mathbf{G} ; 270 \mu \mathrm{m}$ in $\mathbf{H}$.
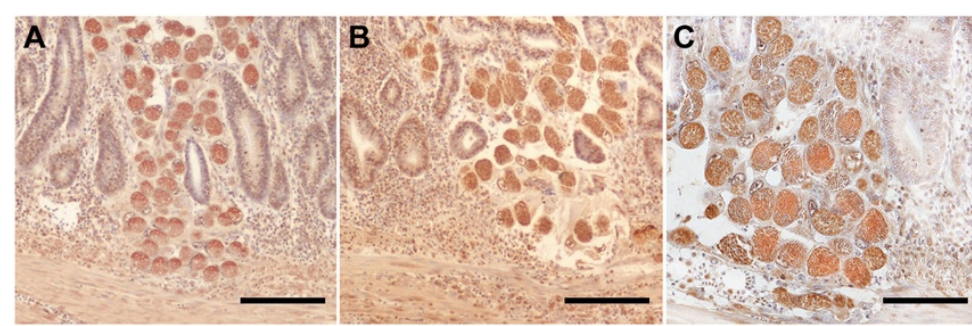

D

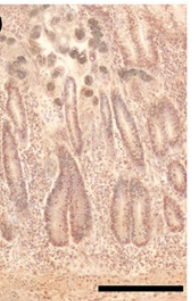

Figure 3 Effect of IL17A Ab on the expression of S100 (A), HSP70 (B), and WASF3 (C) proteins by E. tenella schizonts. Light micrographs showing cecal wall sections taken 5 dpi from untreated chickens $(\mathbf{A}, \mathbf{B}, \mathbf{C})$. Samples taken from IL 17A Ab-treated chickens lacked of positivity for those three motility-related proteins as exemplified in $\mathbf{D}$, where schizonts are devoid of positivity for S100 protein. Note the expression of those proteins versus the lack of positivity in IL17A Ab-treated chickens (D). Bars indicate: $200 \mu \mathrm{m}$ in A, B and D; $100 \mu \mathrm{m}$ in C. 


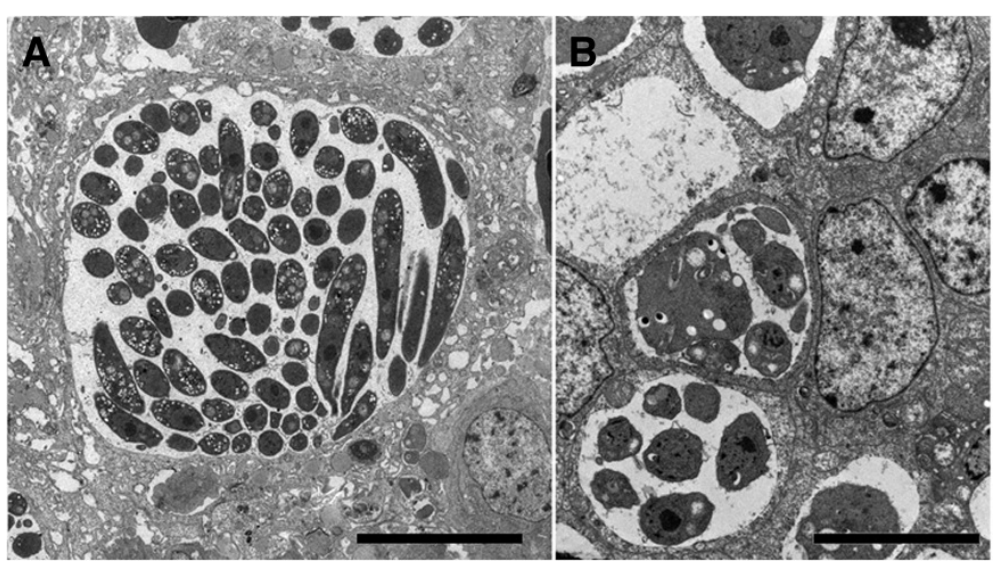

Figure 4 Electron microscopy of hypertrophied and modified host cells harboring mature $E$. tenella schizonts. Samples taken at 5 dpi from chickens that were not (A) or were given (B) IL 17A Ab. Note the differences in diameter and numbers of merozoites. Bars indicate: $15 \mu \mathrm{m}$ in A; $7 \mu \mathrm{m}$ in $\mathbf{B}$.

\section{Effect of IL17A Ab on serum MMP-9 levels}

Increased MMP-9 levels were present at day 6 pi in sera of untreated and infected chickens, compared with untreated and uninfected chickens (Figure 5). Significantly decreased serum MMP-9 levels were observed in infected chickens that were given IL17A Ab, compared with infected and untreated birds.

\section{Effect of IL17A Ab on E. tenella-stimulated cytokine-producing cells}

CT, PP, and spleen cells of infected chickens that were injected with IL17A Ab had significantly increased numbers of IL2- and IFN $\gamma$-producing cells, compared both with the uninfected/untreated and infected/untreated controls (Figure 6). The numbers of Th1 cytokineproducing cells were greater in CT-derived cells than in PP- or spleen-derived cells. This differential profile of cell response correlates with the site of infection in the intestine by $E$. tenella, the cecum. Infected animals had significantly increased the numbers of IL4- and IL10producing cells in all three types of tissues examined, compared with uninfected chickens. However, administration of IL17A Ab did not alter the numbers of IL4and IL10-producing cells in the CTs, PPs, and spleen, compared with the infected controls that were not given IL17A Ab (Figure 6).

\section{Effect of IL17A Ab on in vivo parameters of protective immunity against $E$. tenella infection}

Infected chickens that were given IL17A $\mathrm{Ab}$ had decreased intestinal lesion scores, compared with infected chickens that were not given IL17A Ab (Table 1).

\section{Discussion}

IL17A exerts critical immunological control of the host response to various infectious pathogens [23,24]. Although IL17A is known to be involved in the host response to protozoal infections [7,9], and its production has been associated with the protective response to coccidial infections [25], the specific effect of IL17A on $E$. tenella infection has not been clearly defined. Indeed, IL17A production has been suggested to be deleterious
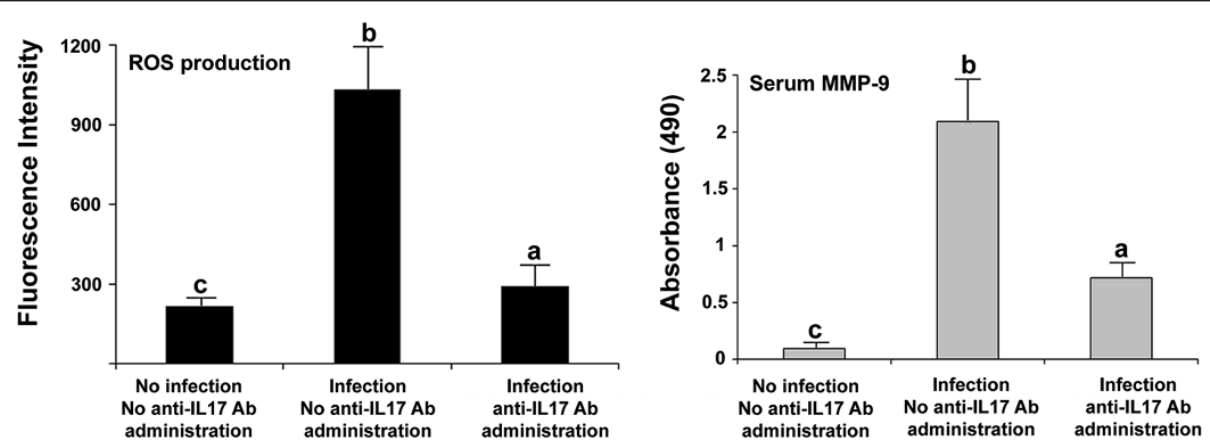

Figure 5 ROS production and serum MMP-9 levels measured by fluorometry and ELISA, respectively. Samples were taken at 6 dpi. Each bar represents the mean \pm SD value from three independent experiments. Within each graph, bars with different letters are significantly different $(P<0.05)$ according to Duncan's multiple-range test. 


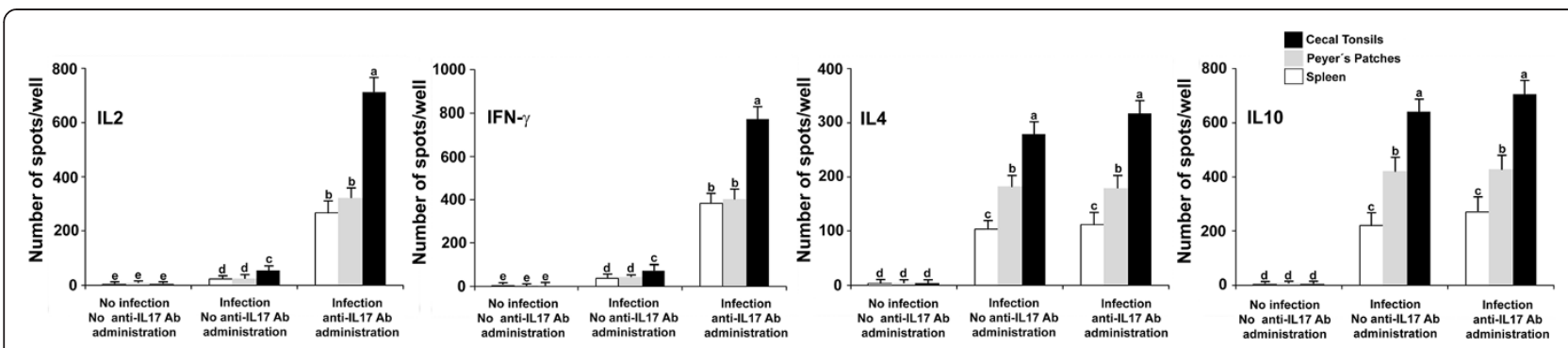

Figure 6 E. tenella antigen-specific $T_{h} 1$ and $T_{h} \mathbf{2}$ cytokine-secreting cells quantified by ELISPOT assay. Samples were taken from the spleen, cecal tonsils, and Peyer's patches at $6 \mathrm{dpi}$. Each bar represents the mean \pm SD value from three independent experiments. Within each graph, bars with different letters are significantly different $(P<0.05)$ according to Duncan's multiple-range test.

in avian coccidiosis [26], indicating the necessity of further research to discern the precise role of IL17A in Eimeria infections. Herein, we provide evidence that IL17A is involved in the initiation and migratory response of epithelial cells harboring E. tenella secondgeneration schizonts during intracellular development. Furthermore, our results indicate that IL17A contributes to the maturation of E. tenella schizonts contributing to severe cecal lesions, as demonstrated by the finding that the in vivo treatment with an IL17A neutralizing Ab led to increased parameters of Th1 immunity and reduced ROS and MMP-9 levels.

It is well known that epithelial cells harboring secondgeneration schizonts migrate deep into the mucosa in order for the schizonts to mature and form secondgeneration merozoites during intracellular development. The present study provides the first evidence that the administration of an IL17A Ab inhibited the migration of parasitized cells and markedly reduced the production of ROS and MMP-9, which facilitate cell migration through the extracellular matrix [10,27]. ROS have been implicated in oxidative stress leading to activation of the cell contractile machinery, which in turn, is responsible for the loss and disorganization of tight junction proteins, responsible for intercellular adhesion of cecal epithelial cells [10]. Treatment of E. tenella-infected chickens with IL17A Ab reduced ROS production, suggesting that the reduction of the migration of parasitized epithelial cells in the crypts is due to the lack of

Table 1 Effect of anti-IL17A Ab on E. tenella infection.

\begin{tabular}{|c|c|}
\hline Treatment group & $\begin{array}{l}\text { Lesion score } \\
\text { (scale of } 0-4 \text { ) }\end{array}$ \\
\hline No infection, no anti-IL17A Ab administration & $0^{a}$ \\
\hline Infection, no anti-IL17A Ab administration & $2.5 \pm 0.49^{b}$ \\
\hline Infection, anti-IL17A Ab administration & $1.1 \pm 0.4^{c}$ \\
\hline \multicolumn{2}{|c|}{$\begin{array}{l}\text { Each value represents the mean } \pm \text { SD of three independent antibody } \\
\text { administration/infection trials. Within each parameter values with different } \\
\text { superscripts are significantly different }(p<0.05) \text { according to Duncan's multiple } \\
\text { range test. The statistical analysis detected significant differences among } \\
\text { experimental groups. Birds infected and inoculated with anti-IL17A Ab showed } \\
\text { significant lower lesion scores than infected and non-inoculated birds }(p<0.05) \text {. }\end{array}$} \\
\hline
\end{tabular}

interference with the intercellular adhesion. A second step for parasitized cells in their migration towards the LP is to traverse through the basement membrane, the structural attachment site for overlying epithelial cells and underlying extracellular matrix and connective tissue. MMPs constitute a family of $\mathrm{Zn}^{2+}$-dependent endopeptidases that regulate the degradation, turnover, and processing of proteins of the extracellular matrix including fibrillar and non-fibrillar collagens, fibronectin, laminin, and basement membrane or interstitial stromal glycoproteins [27,28]. Treatment of E. tenella-infected chickens with IL17A Ab reduced MMP-9 production, suggesting hindered movement of host cells harboring second-generation schizonts into the connective tissue, as evidenced by the increased numbers of host cells containing mature second-generation schizonts near the epithelium lining the crypts. Importantly, in untreated infected chickens, increased MMP-9 production was found compared with uninfected controls. These data, plus the finding that cells harboring second-generation schizonts reached the deepest portion of the cecal mucosa, accumulated close to the MM, and extended into the SM, led us to suggest that the integrity of both intracellular junctional complexes and the basement membrane are impaired as a consequence of the increase in ROS and MMP-9 production during E. tenella infection. Furthermore, increased MMP-9 production facilitated the movement of cells harboring second-generation schizonts through the connective tissue in the LP. These results suggest that during E. tenella infection, IL17A promotes the migration of parasitized epithelial cells by facilitating their separation from the epithelial layer and movement away from the epithelium into the LP.

There is general consensus that the administration of IL17A neutralizing Ab reduces the degree of tissue damage of the cecal wall caused by Eimeria infections $[26,29]$. However, there are controversial reports concerning the effect of IL17A neutralization on fecal oocyst shedding. In murine coccidiosis, Stange et al. [29] reported that neutralization of IL17A production increased E. falciformis oocyst output. In contrast, Zhang et al. 
[26] reported reduced E. tenella oocyst shedding after IL17A neutralization in avian coccidiosis. Our findings are in accordance with the studies by Zhang et al. [26] indicating that the neutralization of IL17A dramatically decreased the numbers of merozoites and reduced the severity of the cecal tissue damage in cecal coccidiosis. Furthermore, our study suggests that decreased merozoite multiplication and cecal tissue damage may be caused by the reduced motility of cells containing secondgeneration schizonts. The numbers of oocyst produced depend upon the numbers of merozoites formed during schizogony [30]. We found that schizonts from IL17A Ab-treated chickens were small, and that merozoite numbers were reduced, compared to untreated infected chickens. In addition, parasitized epithelial cells did not move deep into the LP and did not trespassed the MM in IL17A Ab-treated chickens. Thus, limited migration caused less adverse effects, such as decreased disruption of blood vessels, and reduced tissue destruction and cell infiltration. On the basis of the findings discussed above, in infected chickens treated with IL17A Ab, reduced merozoite formation was associated with the inhibition of migration of parasitized cells and the impairment of schizont maturation.

In E. tenella infections, the migration of epithelial cells harboring second-generation schizonts is required for schizont maturation. Whereas the host cells moves through the LP, schizonts reproduce asexually by multiple fission to form a number of infective merozoites. These escape from the host cell and invade new cells [31]. The present findings also showed that schizonts from infected chickens not given the neutralizing $\mathrm{Ab}$ expressed S100, WASF3, and HSP70 proteins. WASF3 coordinates the development of lamellipodia at the leading edges of cells, and its loss prevents cell motility [32]. S100 and WASF3 are involved in actin polymerization and in cell motility $[15,33,34]$. HSP70 is a chaperone protein associated with both cell motility [15] and parasite capability to adapt to the new environment in the host [35]. HSP70 and its associated proteins involved in cytoskeleton rearrangement have been reported as regulators of infectivity and pathogenicity of $E$. tenella $[36,37]$. In our study, schizonts from infected chickens treated with IL17A Ab did not express these proteins, suggesting that during $E$. tenella infection locally produced IL17A promotes the expression of S100, WASF3, and HSP70 as the merozoites reach their infective capability.

Our study, as well as previously reported findings $[26,29]$, demonstrates that neutralization of IL17A increased the Th1 cytokines, IL2, IFN $\gamma$, and IL12. These results may be associated with the fact that Th17 cells are antagonistic of Th1 cells. Indeed, IL17A and IL22, a Th17 cell-associated proinflammatory cytokine, have been reported to inhibit the production of Th1 mediated cytokines [38]. Since the Th1 response is the most efficient host response against Eimeria infection, it is conceivable that neutralization of IL17A increases the efficacy of the Th1 response against E. tenella. Although Th17 cells have been reported to be the major effector $\mathrm{T}$ cells that provide immunity in the intestine [39] against many potential pathogens $[40,41]$, the exact roles of Th17 cells in the intestine are incompletely understood. Studies by Zhang et al. [26] and Stange et al. [29], in addition to our current report, support the notion that IL17A has a role in E. tenella pathogenesis. In summary, the present study confirms and extends previous observations in avian coccidiosis that neutralization of IL17A reduced $E$. tenella multiplication and diminished tissue lesions on the basis of a herein demonstrated reduction of parasitized epithelial cell motility. Consequently, IL17A might be a potential therapeutic target for avian coccidiosis control.

\section{Abbreviations}

LP: Lamina propria; MM: Muscularis mucosa; CT: Cecal tonsil; PP: Peyer's patch; Ab: Antibody; IL17A: Interleukin 17A; ROS: Reactive oxygen species; MMP-9: Matrix metalloproteinase-9; WASF3: Wiskott-Aldrich syndrome protein family member 3; HSP70: Heat shock protein 70; HRP: Horseradish peroxidase; TMB: Tetramethylbenzidine dihydrochloride; ABC: Avidin-biotin peroxidase complex; DAB: Diaminobenzidine; DCFDA: Dichlorofluorescein diacetate; ELISPOT: Enzyme-linked immunosorbent spot; SD: Standard deviation

\section{Competing interests}

The authors declare that they have no competing interests.

\section{Authors' contributions}

HSL, EC, CSA conceived and designed the study. JQ, MG participated in its coordination. AR, JQ, EC immunized and challenged the chickens and performed their clinical examination. HSL, EPL developed anti-chicken IL17A $I L-4, I L-10$, and IFN- $\gamma$ antibodies and interpreted the immunological results. $M G, E C, A R, J Q, C S A$ participated in the collection and processing of the samples, and carried out the histopathological and immunological analysis. JQ, AR, CSA performed the statistical analyses and interpreted the results. HSL, $E P L, M G$, wrote the manuscript; with inputs from all authors. All authors read and approved the manuscript.

\section{Acknowledgments}

This investigation was partially funded by Grant A46 from the Research Council of Aragón (Spain) and USDA-CSREES proposal 2005-01812 (US Veterinary Immune Reagent Network).

\section{Author details}

'Department of Animal Pathology, Faculty of Veterinary Sciences, University of Zaragoza, Zaragoza, Spain. ${ }^{2}$ Animal Biosciences and Biotechnology Laboratory, Beltsville Agricultural Research Center, Agricultural Research Service, U.S. Department of Agriculture, Beltsville, MD 20705, USA. ${ }^{3}$ Department of Pediatrics, University of Maryland School of Medicine, Baltimore, MD 21201, USA

Received: 25 November 2013 Accepted: 12 February 2014 Published: 26 February 2014

\section{References}

1. Lopez-Bernad F, del Cacho E, Gallego M, Quílez J, Sánchez-Acedo C: Immunohistochemical identification of the cells parasitized by secondgeneration schizonts of Eimeria tenella. Parasitol Res 1998, 84:132-135. 
2. Steinman $L$ : A brief history of $T(H) 17$ the first major revision in the $T(H) 1 /$ $\mathrm{T}(\mathrm{H}) 2$ hypothesis of T cell-mediated tissue damage. Nat Med 2007, 13:139-145.

3. Chen Z, O'Shea JJ: Th17 cells: a new fate for differentiating helper T cells. Immunol Res 2008, 41:87-102.

4. Ivanov II, Atarashi K, Manel N, Brodie EL, Shima T, Karaoz U, Wei D, Goldfarb KC, Santee CA, Lynch SV, Tanoue T, Imaoka A, Itoh K, Takeda K, Umesaki Y, Honda K, Littman DR: Th17 cells secrete interleukin-17 (IL-17), IL-17F, and $\mathrm{IL}-22$ and have significant roles in protecting the host from bacterial and fungal infections, particularly at mucosal surfaces. Induction of intestinal Th17 cells by segmented filamentous bacteria. Cell 2009, 139:485-498.

5. Hong YH, Lillehoj HS, Lee SH, Dalloul RA, Lillehoj EP: Analysis of chicken cytokine and chemokine gene expression following Eimeria acervulina and Eimeria tenella infections. Vet Immunol Immunopathol 2006, 114:209-223.

6. Hong YH, Lillehoj HS, Lillehoj EP, Lee SH: Changes in immune-related gene expression and intestinal lynphocite subpopulations following infection of chickens. Vet Immunol Immunopathol 2006, 114:259-272.

7. Kelly MN, Kolls JK, Happel K, Schwartzman JD, Schwarzenberger P, Combe C, Moretto M, Khan IA: Interleukin-17/interleukin-17 receptor-mediated signaling is important for generation of an optimal polymorphonuclear response against Toxoplasma gondii infection. Infect Immun 2005, 73:617-621.

8. Rudner XL, Happel Kl, Young EA, Shellito JE: Interleukin-23 (IL-23)-IL-17 cytokine axis in murine Pneumocystis carinii infection. Infect Immun 2007, 75:3055-3061.

9. Miyazaki $Y$, Hamano S, Wang S, Shimanoe $Y$, Iwakura $Y$, Yoshida H: IL-17 is necessary for host protection against acute-phase Trypanosoma cruzi infection. J Immunol 2010, 185:1150-1157.

10. Huppert J, Closhen D, Croxford A, White R, Kuling P, Pietrowski E, Bechmann I, Becher B, Luhmann HJ, Waisman A, Kuhlmann CRW: Cellular mechanisms of IL-17-induced blood-brain barrier disruption. FASEB J 2010, 24:1023-1034

11. Schreibelt G, Musters RJP, Reijerkerk A, de Groot IR, van der Pol SMA Hendriks EML, Döpp ED, Dijkstra CD, Drukarch B, Vries HE: Lipoic acid affects cellular migration into the central nervous system and stabilizes blood-brain barrier integrity. J Immunol 2006, 177:2630-2637.

12. Matuscvicius D, Livisäkk P, He P, Kostulas N, Ozenci V, Fredrikson S, Link H: Interleukin-17 mRNA expression in blood and CSF mononuclear cells is augmented in multiple sclerosis. Mult Scler 1999, 5:101-104.

13. Schreibelt G, Kooij G, Reijerkerk A, van Doorn R, Gringhuis SI, van der Pol S, Weksler BB, Romero IA, Couraud P, Piontck J, Dijkstra CD, Ronken E, Vries HE: Reactive oxygen species alter brain endothelial tight junction dynamics via RhoA, PI3 kinase, and PKB signaling. FASEB J 2007, 21:3666-3676.

14. Yoo J, Chang HH, Bae YH, Seong $\mathrm{CH}$, Choe NH, Lillehoj HS, Park JH, Min W: Monoclonal antibodies reactive with chicken interleukin-17. Vet Immunol Immunopathol 2008, 121:359-363.

15. Teng Y, Ngoka L, Mei Y, Lesson L, Cowell JK: HSP90 and HSP70 proteins are essential for stabilization and activation of WASF3 metastasispromoting protein. J Biol Chem 2012, 287:10051-10059.

16. Suetsugu S, Miki H, Takenawa T: Identification of two human WAVW/SCAR homologues as general actin regulatory molecules that associate with the Arp2/3 complex. Biochem Biophys Res Commun 1999, 260:296-302.

17. Donato R, Giambanco I: Interaction between S-100 proteins and steadystate and taxol-stabilized microtubules in vitro. J Neurochem 1989 52:1010-1017

18. Raether W, Hofmann J, Uphoff M, Eckert HS: In vitro cultivation of avian Eimeria species: Eimeria tenella. In Biotechnology, Guidelines on techniques in coccidiosis research. Edited by Eckert J, Braun R, Shirley MW, Coudert P. Brussels: European Commission; 1995:79-84

19. Shirley MW: Eimeria and Isospora. In Biotechnology, Guidelines on techniques in coccidiosis research. Edited by Eckert J, Braun R, Shirley M, Coudert P. Brussels: European Commission; 1995:4-7.

20. Johnson J, Reid WM: Anticoccidial drugs lesion scoring techniques in battery and floor-pen experiments with chickens. Exp Parasitol 1970, 28:30-36.

21. del Cacho E, Gallego M, López-Bernard F, Sánchez-Acedo C, Lillehoj HS: Isolation of chicken follicular dendritic cells. J Immunol Methods 2008, 334:59-69.

22. del Cacho E, Gallego M, Lillehoj HS, López-Bernard F, Sánchez-Acedo C: Avian follicular and interdigitating dendritic cells: isolation and morphologic, phenotypic, and functional analyses. Vet Immunol Immunopathol 2009, 129:66-75.
23. Huang $W, N a$ L, Fidel PL, Schwarzenberger P: Requirement of interleukin$17 \mathrm{~A}$ for systemic anti-Candida albicans host defense in mice. J Infect Dis 2004, 190:624-631.

24. Khader SA, Bell GK, Pearl JE, Fountain JJ, Rangel-Moreno J, Cilley E, Shen F, Eaton SM, Gaffen SL, Swain SL, Locksley RM, Haynes L, Randall TD, Cooper AM: IL-23 and IL-17 in the establishment of protective pulmonary CD4+ T cell responses after vaccination and during Mycobacterium tuberculosis challenge. Nat Immunol 2007, 8:369-377.

25. Geriletu, Lixin X, Xurihua, Xiangrui L, Geriletu G, Lixin X, Xurihua X, Xiangrui $L$ : Vaccination of chickens with DNA vaccine expressing Eimeria tenella MZ5-7 against coccidiosis. Vet Parasitol 2011, 177:6-12.

26. Zhang L, Liu R, Song M, Hu Y, Pan B, Cai J, Wang M: Eimeria tenella: Interleukin 17 contributes to host immunopathology in the gut during experimental infection. Exp Parasitol 2013, 133:121-130.

27. Nagase H, Woessner JF: Matrix metalloproteinases. J Biol Chem 1999, 274:21491-21494.

28. Kim YH, Kwon HJ, Kim DS: Matrix metalloproteinase 9 (MMP-9)dependent processing of $\beta$ ig-h3 protein regulates cell migration, invasion, and adhesion. J Biol Chem 2012, 287:38957-38969.

29. Stange J, Hepworth MR, Rausch S, Zajic L, Kühl AA, Uyttenhove C, Renauld JC, Hartmann S, Lucius R: IL-22 Mediates host defense against an intestinal intracellular parasite in the absence of IFN-g at the cost of Th17-driven immunopathology. J Immunol 2012, 188:2410-2418.

30. Shirley MW, Bedrnik P: Live attenuated vaccines against avian coccidiosis: success with precocious and egg-adapted lines of Eimeria. Parasitol Today 1997, 13:481-484.

31. Fernando MA, Lawn AM, Rose EM, Al-Attar M: Invasion of chicken caecal and intestinal lamina propria by crypt epithelial cells infected with coccidia. Parasitology 1983, 86:391-398.

32. Sossey-Alaoui K, Li X, Ranalli TA, Cowell JK: WAVE3-mediated cell migration and lamellipodia formation are regulated down-stream of phosphatidylinositol 3-kinase. J Biol Chem 2005, 280:21748-21755.

33. Helfman DM, Kim EJ, Lukanidin E, Grigorian M: The metastasis associated protein S100A4: role in tumour progression and metastasis. $\mathrm{Br} J$ Cancer 2005, 92:1955-1958.

34. Berge G, Mælandsmo GM: Evaluation of potential interactions between the metastasis-associated protein S100A4 and the tumor suppressor protein p53. Amino Acids 2011, 41:863-873.

35. Maresca B, Carratú L: The biology of the heat shock response in parasites. Parasitol Today 1992, 8:260-266.

36. Bejon PA, Bannister LH, Fowler RE, Fookes RE, Webb SE, Wright A, Mitchell GM: A role for microtubules in Plasmodium falciparum merozoite invasion. Parasitology 1997, 114:1-6.

37. del Cacho E, Gallego M, López-Bernad F, Quílez J, Sánchez-Acedo C: Differences in hsp70 expression in the sporozoites of the original strain and precocious lines of Eimeria tenella. J Parasitol 2005, 91:1127-1131.

38. Prabhala RH, Pelluru D, Fulciniti M, Prabhala HK, Nanjappa P, Song W, Pai C, Amin S, Tai YT, Richardson P, Ghobrial I, Treon ST, Daley JF, Anderson KC, Kutok JL, Munshi NC: Elevated IL-17 produced by TH17 cells promotes myeloma cell growth and inhibits immune function in multiple myeloma. Blood 2013, 15:5385-5392.

39. Wang C, Kang SG, Hogenesch H, Love PE, Kim CH: Retinoic acid determines the precise tissue tropism of inflammatory Th17 cells in the intestine. J Immunol 2010, 184:5519-5526.

40. Hung LY, Velichko S, Huang F, Thai P, Wu R: Regulation of airway innate and adaptive immune responses: the IL-17 paradigm. Crit Rev Immunol 2008, 28:269-279.

41. Iwakura Y, Nakae S, Saijo S, Ishigame H: The roles of IL-17A in inflammatory immune responses and host defense against pathogens. Immunol Rev 2008 , 226:57-79.

doi:10.1186/1297-9716-45-25

Cite this article as: del Cacho et al:: IL-17A regulates Eimeria tenella schizont maturation and migration in avian coccidiosis. Veterinary Research 2014 45:25. 